\title{
História da saúde da criança: conquistas, políticas e perspectivas
}

\author{
History of the child's health: conquers, policies and perspectives \\ Historia de la salud del niño: conquistas, políticas y perspectivas
}

\section{Juliane Pagliari Araújo', Rosane Meire Munhak da Silva", Neusa Collet"I", Eliane Tatsch Neves ${ }^{\text {IV }}$ Beatriz Rosana Gonçalves de Oliveira Toso ${ }^{\mathrm{v}}$, Cláudia Silveira Viera ${ }^{\mathrm{v}}$}

\author{
'Instituto Federal de Educação, Ciência e Tecnologia do Paraná. Londrina-PR, Brasil. \\ "Universidade Estadual do Oeste do Paraná, Curso de Enfermagem. Foz do Iguaçu-PR, Brasil. \\ II' Universidade Federal da Paraíba, Programa de Pós-Graduação em Enfermagem. João Pessoa-PB, Brasil. \\ Iv Universidade Federal de Santa Maria, Programa de Pós-Graduação em Enfermagem. Santa Maria-RS, Brasil. \\ ${ }^{\vee}$ Universidade Estadual do Oeste do Paraná, Programa de Pós-Graduação em Biociências e Saúde. Cascavel-PR, Brasil.
}

Submissão: 08-09-2014 Aprovação: 21-10-2014

\section{RESUMO}

Objetivou-se descrever e refletir sobre os aspectos relacionados à história social e às políticas públicas de assistência à saúde da criança no Brasil. Realizou-se breve contextualização histórica sobre as transformações no ser criança no Brasil e no mundo, apresentando-se as perspectivas referentes às políticas públicas de saúde da criança no âmbito nacional. Observou-se que a evolução histórica da participação da criança na sociedade encontra-se atrelada às mudanças nas políticas públicas de assistência, traduzida em queda da mortalidade infantil, aliada a desafios como a redução da morbimortalidade por agravos perinatais e causas evitáveis. Os avanços e conquistas na saúde da criança encontram-se em um movimento de mudança paradigmática para um modelo de construção de redes e da integralidade do cuidado. Esse contexto aponta a necessidade de formação de recursos humanos para esta área, tendo em vista à promoção e prevenção em saúde, assim como uma melhor qualidade de vida dessa população.

Descritores: Saúde da Criança; Política de Saúde; Enfermagem Pediátrica; História.

\section{ABSTRACT}

The aim of this study was describing and reflecting about the aspects related to the social history and public policies for the children's health assistance in Brazil. A brief historical contextualization was realized concerning changes on the way the society views the child in Brazil and around the world, also perspectives considering public policies for the children's health in the national context were presented. It was possible to identify that the historical evolution of the child participation in the society is linked to the changes in the assistance public policies, which were demonstrated in the child death decrease and associated to challenges, like the morbimortality reduction caused by perinatal injuries and avoidable causes. The advances and conquers in the child's health are evolved in a paradigmatic change movement into a model of a net formation and a comprehensiveness care. This context requires the human resources preparation for such area, based on the health promotion and prevention, as well as a better quality of life of the population. Key words: Child Health; Health Policy; Pediatric Nursing; History.

\section{RESUMEN}

El objetivo del estudio fue describir y reflexionar acerca de los aspectos relacionados con la historia social y las políticas públicas de asistencia de salud de niños en Brasil. Una breve contextualización acerca de las transformaciones en el modo de ser niño en Brasil y en el mundo, así como las perspectivas relacionadas a las políticas públicas de salud del niño en el contexto nacional. La evolución histórica de la participación del niño en la sociedad encuentra-se vinculada a las modificaciones de las políticas públicas de asistencia, que se mira en la reducción de la mortalidad infantil, acercada de desafíos como la reducción de la morbimortalidad por injurias perinatales y causas evitables. Los avanzos y conquistas na salud del niño se encuentran en uno movimiento de modificacion paradigmática para un modelo de construcción de redes y de la integralidad del cuidado. En este contexto se observa la necesidad de formación de recursos personales para esta área, con base en la promoción y prevención en salud y una mejor cualidad de vida de esa población.

Palabras clave: Salud del Niño; Política de Salud; Enfermería Pediátrica; Historia.

\section{AUTOR CORRESPNDENTEＲosane Munhak Silva E-mail: zanem2010@hotmail.com}




\section{INTRODUÇÃO}

As crianças por muitos anos foram tratadas da mesma forma que adultos, sem nenhuma consideração pelos aspectos relacionados ao crescimento e desenvolvimento infantil. Nesse contexto, foram colocadas no lugar de infante (quietinhos, tradução livre do francês), sem voz, como objetos da esfera doméstica. A infância não era percebida pela família e nem pelo Estado como uma etapa do ciclo vital, com necessidades singulares ${ }^{(1)}$. Entretanto, no decorrer dos séculos a criança passou a ser vista socialmente, com particularidades significativas que exigiram transformações sociais, econômicas e políticas.

Transformações ocorridas na Europa, durante o século XVIII, conduziram ao estabelecimento de novas relações de poder entre Estado e sociedade, principalmente com o advento da Revolução Industrial, que levou à substituição do trabaIho individual e manufatureiro pela produção baseada no uso de máquinas. Isto ocasionou a necessidade cada vez maior de mão-de-obra, surgindo as primeiras políticas públicas de saúde, voltadas em sua essência, ao controle social, serviços de saneamento e de saúde ${ }^{(2)}$. Consequentemente, o modo de produção capitalista, que fez o aumento da população tornar-se objeto do Estado, que tinha como meta a expansão da produtividade e o fortalecimento do exército, esteve diretamente relacionado à estruturação e evolução dos serviços de saúde ${ }^{(3)}$.

Deste modo, o reconhecimento da criança enquanto ser biopsicossocial, assim como, seus direitos enquanto cidadão foi se delineando ao longo da história, paralelos a assistência à saúde a este segmento populacional, o qual passou por transformações e ainda permanece em constante construção.

Vislumbrando a apreensão dessas transformações, o presente artigo tem por objetivo descrever e refletir sobre os aspectos relacionados à história social e às políticas públicas de assistência à saúde da criança no Brasil.

\section{A HISTÓRIA SOCIAL DA CRIANÇA}

A criança, ao longo dos anos, evidenciou inúmeras transformações e ocupou diferentes posições na sociedade. Essas transformações a levou a enfrentar diversas situações de vida e de saúde para, finalmente, depois de muitos anos, ser considerada sujeito social com características particulares ${ }^{(1)}$.

No século XI, a criança era mundialmente percebida apenas como um adulto em miniatura, sem características ou particularidades individuais, principalmente pelo fato de não possuir a linguagem bem desenvolvida. Pelo deslumbramento religioso configurado na imagem do menino Jesus, em anjos e na figura morta, a criança passou a ser notada entre os adultos, mas ao mesmo tempo, permaneceu anexa a estes, envolvida em jogos ou trabalho. Sua imagem, por volta do século XV, começou a ser retratada por pintores da época, não por fazer parte de um grupo que necessitasse de atenção específica da sociedade, mas por sua beleza e graciosidade ${ }^{(1,4)}$.

No Brasil, essa realidade não se mostrou diferente. $O$ período colonial, por exemplo, foi marcado por muitas barbáries que contribuíram efetivamente para os altos índices de
Mortalidade Infantil (MI), os quais se mantinham próximos a $70 \%$. As crianças eram vistas como um instrumento para as famílias, agentes passivos, amedrontadas pelos cruéis castigos físicos, permanecendo constantemente submetidas ao serviço e ao poder paternos, quando não abandonadas em casas de caridade ou hospitais $^{(5-6)}$.

Como se não bastasse a indiferença e as crueldades a que essas crianças eram submetidas, as precárias condições sanitárias e sociais colaboraram com o processo de adoecimento, pois, muitas viviam em um único cômodo, sem arejamento ou sol, colaborando para o quadro crítico da morbimortalidade infantil ${ }^{(1,4)}$.

Ainda neste período, as mulheres, no processo de parturição, eram assistidas por parteiras inexperientes e, em seguida, suas crianças eram cuidadas por escravas, denominadas amas-secas. Estas por sua vez, devido a sua condição na sociedade da época, se alimentavam mal, apresentavam péssimas condições de higiene e seus lares eram desprovidos de saneamento básico. Todos esses fatores possibilitavam a transmissão de doenças e favoreciam o adoecimento das crianças ${ }^{(1,5)}$.

Outro agravante eram as precárias condições nutricionais e de vestimenta a que as próprias crianças eram submetidas, sendo que, a alimentação e o vestuário adulto eram prioritários entre as comunidades da época(1). Com isso, acentua-se o processo de adoecimento infantil e, quando isso acontecia, eram levadas tardiamente aos médicos.

No século XVII a criança começou a ocupar espaço no âmbito social, pois é neste período que as famílias demonstraram sentimentos de carinho e amor ao infante. A sociedade passou a perceber que a criança representava o centro para as famílias, inclusive plausível de mudanças físicas e mentais. Nessa mesma época foram encontrados os primeiros registros da linguagem infantil(1).

Entretanto, mesmo com o reconhecimento e importância do cuidado infantil, o abandono permaneceu por muito tempo como uma prática aceita pela sociedade. No século XVIII, entre os motivos de abandono pode-se evidenciar a extrema pobreza, o nascimento de um filho sem um casamento, o abandono de filhos de escravas para que estas pudessem ser mães de leite para os filhos das famílias da elite, adoecimento ou morte dos pais. Nesses casos, as crianças eram deixadas em um local chamado Roda dos Enjeitados, ou, Rodas dos Expostos, ou, Rodas. Estes artefatos cilíndricos eram fixados em instituições de caridade ou hospitais, possibilitando uma abertura interna ou externa quando rodados, onde as crianças eram deixadas e, o anonimato de quem as deixava era mantido(4-5).

Nesse mesmo período, a cada 100 crianças livres que nasciam no Brasil, cinco eram abandonadas, ou seja, expostas nas Rodas e um terço eram consideradas ilegítimas. Desse modo, os ilegítimos e os expostos somavam $40 \%$ dos bebês nascidos vivos. Essa exposição de crianças apresentou uma elevação bastante grave, principalmente entre os anos de 1850 e $1860^{(5)}$.

Os sistemas de Rodas pertenciam às instituições caritativas que acolhiam todas as crianças abandonadas. Estas instituições buscavam de forma precária, cuidá-las oferecendo-lhes abrigo e alimentação. As crianças menores eram alimentadas por amas de leite que recebiam uma pequena quantia para 
amamentar os desvalidos. Estas crianças eram entregues às amas, que as mantinham em suas casas, mas também eram desprovidas de instalações e condições de higiene adequadas. Quando as meninas cresciam, eram devolvidas às instituições caritativas, para em seguida, serem encaminhadas às Casas de Recolhimento, as quais preconizavam o cuidado para manter a integridade da moça e os bons costumes, e ensinar-lhes tarefas domésticas, garantindo-lhes assim, um casamento. Já os meninos, quando não encaminhados às instituições militares, geralmente eram deixados à sua própria sorte nas ruas ${ }^{(5)}$.

Em um contexto geral, no período do Brasil Colônia, nem a Igreja ou o Estado assumiram a responsabilidade pela criança abandonada. Foi a sociedade organizada ou não, que se preocupou com a sorte destes pequeninos desvalidos e sem família. Assim, a história da criança abandonada brasileira se dividiu em três fases, a saber, Caritativa, até meados do século XIX; Filantrópica, até a década de 1960 e Estado do Bem Estar Social, últimas décadas do século XX, fase esta em que a criança torna-se sujeito de direito(5).

Outra forma de separação das crianças dos pais aconteceu no século XIX com base nas concepções higienistas de proteger as crianças de suas próprias famílias, pois estas necessitavam ser cuidadas, amparadas e educadas por colégios internos ou internatos, prevenindo os males e evitando as mortes prematuras $^{(6)}$.

As iniciativas para redução da $\mathrm{Ml}$ apresentaram pouco sucesso neste período, visto que os índices permaneceram elevados. As famílias pouco entendiam o seu papel junto à criança. Vagarosamente começaram a compreender que a própria família deveria ajudar a criança a tornar-se homem ou mulher, pois se constitui em espaço de sobrevivência e evolução para as crianças, servindo de matriz para a formação de um adulto $^{(7)}$. Assim, a família é o primeiro grupo social do qual a criança faz parte, promovendo um ambiente indispensável para prover a sobrevivência e proteger integralmente a criança. No entanto, esta pode ser afetada pelo incremento socioeconômico e pelos impactos de interferências gerados por políticas e ações do Estado. Para tanto, a condição de vulnerabilidade social - a pobreza, não pode ser considerada a única causa que leve à perda ou abandono de um filho ${ }^{(8)}$.

Só foi possível identificar mudanças concretas nos índices de $\mathrm{MI}$ quando a sociedade tomou consciência da situação da criança e os serviços públicos se responsabilizaram pelas mesmas. Assim, teve início o trabalho efetivo de elaboração de políticas públicas e investimentos na saúde materno-infantil, com ações educativas de vigilância e preventivas, focadas na criança e na família.

\section{AS POLÍTICAS PÚBLICAS DE SAÚDE DA CRIANÇA NO BRASIL}

A proposta de uma política pública de saúde resulta de processos históricos, lutas e reinvindicações, na qual a população e os governantes estão envolvidos e emerge por meio de debates sobre os direitos humanos num contexto global ou local ${ }^{(9)}$, bem como, para diversos seguimentos como a saúde da criança.
Na década de 1920, as autoridades públicas e privadas demonstraram preocupação com o adoecimento infantil, deixando de ser apenas preocupação de entidades caritativas. Especificamente em 1920, a criança, por ser considerada dependente dos trabalhadores das indústrias, recebia assistência médica de acordo com as propostas impostas pelos médicos contratados por proprietários destas indústrias. Nessa época, iniciaram-se discussões a respeito do aleitamento materno, visto que, se as crianças menores permanecessem doentes, aumentaria o número de faltas entre trabalhadoras nas indústrias. Para tanto, o estímulo ao aleitamento materno teve como meta reduzir o adoecimento infantil para que suas mães cumprissem com a jornada de trabalho proposta(10-12).

Entre 1930 e 1940, iniciaram-se os programas de proteção à maternidade, à infância e à adolescência, todos submetidos às propostas do Departamento Nacional da Criança (DNCr). Foram instituídas algumas ações de vigilância e educativas, envolvendo a mulher em todo ciclo gravídico-puerperal. Não obstante, as ações instituídas à saúde da criança apresentaram apenas o caráter curativo e individualizado, sendo desenvolvidas em hospitais privados ou centros médicos de grandes indústrias $^{(10-11)}$. Essas ações iniciaram com foco voltado à diminuição do absenteísmo das mães no trabalho e sua evolução ocorreu atrelada às relações de poder entre as entidades patronais e a administração pública.

Neste contexto, por muitos anos o Ministério da Educação e o Ministério da Saúde (MS) permaneceram interligados, desenvolvendo ações e estratégias para a saúde da criança. Somente em 1953 ocorreu o desmembramento desses ministérios. Após a divisão, o MS assumiu a responsabilidade do DNCr. Entre os seus primeiros passos, cabe destacar a destituição do DNCr, em 1969, e a criação, em 1970, da Coordenação de Proteção Materno-Infantil, a qual apresentou como proposta o planejamento, orientação, coordenação, controle e fiscalização das ações de proteção à maternidade, à infância e à adolescência ${ }^{(11)}$. Nesse período os índices de MI encontravam-se altos, pois alcançavam números preocupantes chegando a 120,7/1000 Nascidos Vivos (NV), sendo que a criança era assistida apenas em questões pontuais decorrentes das condições agudas de saúde ${ }^{(13)}$.

Na década de 1970, foi implantado o Programa Nacional de Saúde Materno-Infantil, apresentando como objeto a redução da morbimortalidade entre crianças e mães. Iniciaram as ações com caráter preventivo, porém, pautadas em métodos centralizadores que desconsideravam a diversidade regional existente no país ${ }^{(10-11)}$. No fim dessa década, a Coordenação de Proteção Materno-Infantil passou a chamar-se Divisão Nacional de Saúde Materno-Infantil (DINSAMI), tornandose responsável, em nível central, pela assistência à saúde da mulher, da criança e do adolescente ${ }^{(11)}$. No entanto, não se observaram grandes mudanças nos índices de $\mathrm{MI}$ no fim desta década, pois se contabilizava 113/1000 NV(13).

Com vistas a mudar a assistência à saúde da criança no país e em busca do cuidado integral, por volta dos anos de 1980, identificou-se como necessidade o acompanhamento do processo de crescimento e desenvolvimento de todas as crianças. Assim, o MS elaborou o Programa de Assistência 
Integral à Saúde da Mulher e da Criança (PAISMC), no qual os serviços deveriam estar preparados para resolver todos os problemas que poderiam afetar a saúde materno-infantil. Para tanto, estabeleceu-se, nesse período, cinco ações básicas para o atendimento às crianças brasileiras: aleitamento materno e orientação familiar sobre a alimentação em situação de desmame; estratégias para o controle das afecções respiratórias agudas; imunização básica; controle efetivo das doenças diarreicas e, por último, o acompanhamento profissional do crescimento e do desenvolvimento infantil(10-11).

De forma geral, nas décadas de 1980 e 1990, houve muitas conquistas sociais no âmbito da saúde, por meio da Constituição Federal de 1988, das Leis Orgânicas Municipais e, posteriormente, as Leis Orgânicas 8.080 e 8.142 de 1990, as quais contribuíram profundamente para delinear as transformações no modelo de saúde brasileiro ${ }^{(12)}$, bem como no que diz respeito à saúde da criança. Esse conjunto de ações proporcionou um declínio importante da MI, pois nesta época (1990) os índices alcançaram 47,7/1000 NV(13), contudo, ainda existia um longo caminho a percorrer.

O sistema de saúde no Brasil, por muitos anos, manteve a saúde da criança interligada à saúde materna pela Política de Atenção à Saúde Materno-Infantil. A partir de 1984, o Brasil implantou o Programa de Assistência Integral à Saúde da Criança (PAISC) como estratégia de enfrentamento às adversidades nas condições de saúde da população infantil, especificamente no que se refere à sua sobrevivência. Foi criado com o objetivo de promover a saúde, de forma integral, priorizando crianças pertencentes a grupos de risco e procurando qualificar a assistência e aumentar a cobertura dos serviços de saúde. As ações abrangiam acompanhamento do crescimento e desenvolvimento; incentivo ao aleitamento materno; controle das doenças diarreicas e das Infecções Respiratórias Agudas (IRAs) e a imunização ${ }^{(14)}$.

A seguir, em 13 de julho de 1990, foi aprovada a Lei $\mathrm{n}^{\circ}$ 8.069, que dispõe sobre o Estatuto da Criança e do Adolescente (ECA), a partir do qual, os mesmos passaram a adquirir de amplos direitos de proteção de integridade física e psicológica, lazer e bem-estar, devendo ser amparados pela família, comunidade e Estado ${ }^{(12)}$.

Com a implantação em 1991, do Programa de Agentes Comunitários de Saúde (PACS) e, em 1994 do Programa Saúde da Família (PSF) pelo MS, é que a saúde da criança foi efetivamente potencializada. O PACS inspirou-se nas vivências de prevenção de doenças pela aproximação com a comunidade, proporcionando a comunicação e a orientação como meta para reorganizar os serviços de saúde. Já a implantação do PSF, inicialmente concebido como um programa de saúde e, posteriormente, ampliado para uma estratégia de governo, denominada Estratégia Saúde da Família (ESF), buscou reestruturar os serviços de saúde de cada município, pela transformação do modelo hegemônico centrado na medicalização para um modelo focado na promoção da saúde e na participação comunitária. Esta nova forma de fazer saúde descaracteriza a passividade das pessoas e assume a vinculação responsável entre uma equipe de saúde interdisciplinar e sua população ${ }^{(15)}$.

Paralelamente, em 1991, foi instituído o Programa de Assistência à Saúde Perinatal (PROASP), cujo principal objetivo era a atenção perinatal, enquanto responsável pelos cuidados à unidade mãe-feto e ao recém-nascido. Esta proposta organizou a assistência perinatal a fim de regionalizar este atendimento; prover a melhoria da qualidade da assistência ao parto; o incremento da qualidade da assistência ao recém-nascido; instituindo o alojamento conjunto e incentivando o aleitamento materno ${ }^{(3)}$.

Com o intuito de garantir o direito da criança à assistência humanizada e com o objetivo de incentivar, promover e apoiar o aleitamento materno, em 1995, o MS lançou a Iniciativa Hospital Amigo da Criança (IHAC). Uma das estratégias deste programa foi assegurar o pagamento de $10 \%$ a mais sobre a assistência ao parto aos Hospitais Amigos da Criança vinculados ao Sistema Único de Saúde (SUS) ${ }^{(16)}$.

O modelo assistencial da prática obstétrica e neonatal, por muito tempo, esteve centrado no modelo biomédico, hospitalocêntrico e nas práticas curativas. Ainda na atualidade, tal modelo, que se tornou hegemônico, traz, como consequências, dicotomias, como o distanciamento entre o saber científico e o saber popular ${ }^{(4)}$. A IHAC emergiu como meio de integrar a assistência, proporcionando autonomia para a mãe e bebê, principalmente, no que se refere ao parto humanizado; aleitamento materno e consequentemente na redução de doenças e MI.

Em decorrência da diversidade regional existente no país, em 1996, foi adotado principalmente pelas regiões norte e nordeste do Brasil, a Atenção Integrada às Doenças Prevalentes na Infância (AIDPI), surgindo como estratégia para o seguimento da atenção à saúde da criança em sintonia com a atenção primária na perspectiva de uma avaliação dos desencadeantes que afetam a saúde infantil, almejando a qualidade da assistência. Essa nova abordagem teve origem na Organização Mundial de Saúde (OMS) e Fundo das Nações Unidas para a Infância (UNICEF), e apresentava como objetivo a promoção rápida e significativa da redução da MI no Brasil. Centralizou-se em um conjunto de doenças de maior prevalência na infância, tratando-a na coletividade ${ }^{(11,17)}$. A AlDPI resultou em um declínio importante da MI nos estados do norte e nordeste brasileiro, entretanto, tais estados ainda permaneciam com índices elevados quando comparados aos demais estados do país ${ }^{(18)}$.

No final da década de 1990, foi estruturado o Programa de Apoio à Implantação dos Sistemas Estaduais de Referência Hospitalar para Atendimento à Gestante de Alto Risco, quando ocorreu a organização do atendimento a essa gestante. Foram destinados recursos específicos para a compra de materiais e equipamentos, bem como, para o treinamento dos profissionais, com o objetivo de integrar e melhorar a qualidade da assistência no pré-natal e do vínculo entre o pré-natal e o parto ${ }^{(3,16)}$.

Em consideração ao grande número de nascimentos prematuros e nascimentos com baixo peso anualmente em todo mundo, cerca de 20 milhões de crianças e, ao fato de que as principais causas de mortes infantis serem originárias do período perinatal e prematuridade (cerca de $40 \%$ ), o MS lançou, pela Portaria Ministerial $n^{\circ} 693$ de cinco de julho de 2000, a Norma de Atenção Humanizada do Recém-Nascido de Baixo Peso - o Método Canguru. Esta proposta de atenção permitiu o maior contato, ou seja, o contato pele a pele do bebê com 
sua mãe, de forma crescente e com liberdade de tempo, o qual proporciona uma maior participação da família nos cuidados com o recém-nascido, obtendo melhores resultados em sua recuperação ${ }^{(19)}$.

Ainda no início dos anos 2000, foi criado e implantado o Programa Nacional de Humanização do Pré-Natal e Nascimento, por meio da Portaria n 569/2000, tendo como base a garantia do direito à cidadania, portanto, ao acesso, por parte das gestantes e dos recém-nascidos, à assistência à saúde nos períodos pré-natal, parto, puerpério e neonatal, tanto na gestação de baixo como de alto risco, assegurando a integralidade da assistência ${ }^{(3)}$. Destaca-se que em setembro de 2000, o Brasil assumiu, internacionalmente, com mais 189 nações, a meta dos Objetivos do Desenvolvimento do Milênio (ODM) em reduzir dois terços da $\mathrm{Ml}$ até o ano de $2015^{(20)}$, ou seja, apresentar em 2015 um índice de MI de 15,9/1000 NV.

Em 2004, o MS lançou a Agenda de Compromissos para a Saúde Integral da Criança e Redução da Mortalidade Infantil, a qual postulava como diretrizes ações que tinham o intuito de fortalecer o nascimento saudável, o crescimento e desenvolvimento, o combate a distúrbios nutricionais e às doenças prevalentes na infância. Para aprimorar tais ações, o MS propôs linhas de cuidado, as quais permitiram uma visão ampliada dos usuários em todas as dimensões. Essa forma de organizar a assistência aproxima e articula os três níveis de atenção à saúde, primário, secundário e terciário, indicando, proporcionalmente, a construção do cuidado integral à saúde das crianças ${ }^{(21)}$.

Considerando que a criança demanda atenção integral de forma acolhedora e contínua, as linhas de cuidado propostas pelo MS organizaram-se para atendê-las de forma global, assim como às suas famílias, e foram dispostas da seguinte maneira: Ações da saúde da mulher: atenção humanizada e qualificada; Atenção humanizada e qualificada à gestante e ao recém-nascido; Triagem neonatal: teste do pezinho; Incentivo ao aleitamento materno; Incentivo e qualificação do acompanhamento do crescimento e desenvolvimento; Alimentação saudável e prevenção do sobrepeso e obesidade infantil; Combate à desnutrição e anemias carenciais; Imunização; Atenção às doenças prevalentes; Atenção à saúde bucal; Atenção à saúde mental; Prevenção de acidentes, maus-tratos/violência e trabalho infantil; Atenção à criança portadora de deficiência ${ }^{(22)}$.

Com o objetivo de estabelecer uma estratégia nacional para promoção, proteção e apoio ao aleitamento materno, em 2008, o MS lançou a Rede Amamenta Brasil, adotando como proposta de atuação a educação crítico-reflexiva dos profissionais de saúde, abrangendo Unidades Básicas de Saúde (UBS), focado na $E^{2} F^{(23)}$. O estudo ${ }^{(24)}$ realizado no interior de São Paulo, apontou que as UBS que aderiram a Rede Amamenta Brasil, aumentaram significativamente a prevalência de aleitamento materno em crianças menores de seis meses.

Em 2009, o MS mediante a Portaria Ministerial $n^{\circ}$ 2.395/2009 institui a Estratégia Brasileirinhos e Brasileirinhas Saudáveis, a qual além de priorizar o cuidado integral à criança no nascimento e à mãe enfatiza a qualidade de vida das crianças brasileiras. Para isso, devem ser estimuladas suas habilidades físicas, afetivas, cognitivas e sociais, pela oferta de cuidados ampliados, os quais seguem além da sobrevivência.
Devem-se estabelecer relações por meio de políticas transversais e ações comuns entre diversos setores ministeriais, como a educação, o judiciário, a segurança e a ação social ${ }^{(25)}$.

Finalmente, em junho de 2011 foi implantada, pelo MS, a Rede Cegonha, a qual envolve uma rede de cuidados com vistas a garantir segurança e qualidade assistencial à mulher em todo seu ciclo reprodutivo, bem como garantir à criança segurança e o cuidado integral ao nascimento, crescimento e desenvolvimento. Entre suas ações a Rede Cegonha propõe ampliar o acesso, acolhimento e melhoria da qualidade do pré-natal; oferta de transporte adequado no período do pré-natal e no momento do parto; vinculação da gestante à unidade de referência para assistência ao parto, obtendo-se sempre vaga para a gestante e para o bebê; realização de parto e nascimento seguros, por práticas humanizadas e eficientes de atenção; acompanhante no parto, de livre escolha da mulher; atenção integral à saúde da criança de 0 a 24 meses com qualidade e resolutividade e, por último, acesso ao planejamento reprodutivo ${ }^{(26)}$.

Esta ação governamental é parte da política das Redes de Atenção à Saúde (RAS) lançada pela Portaria Ministerial $n^{\circ}$ 4.279/2010 que visa superar o sistema de saúde fragmentado vigente; a promoção da integração sistêmica de ações e serviços de saúde com provisão de atenção contínua, integral, de qualidade, responsável e humanizada e incrementar o desempenho do sistema, em termos de acesso, equidade, eficácia clínica e sanitária; e eficiência econômica para promover a resolutividade nas redes de atenção ${ }^{(27)}$, vislumbra-se então que, as políticas de saúde da criança têm prioridade na atual conjuntura do sistema de saúde do país.

As RAS devem ser resolutivas, ou seja, solucionar $85 \%$ dos problemas comuns à saúde, ser coordenadoras de fluxos e contrafluxos de usuários, instrumentos e informações nas redes, serem responsáveis pela saúde dos usuários adscritos nas redes e nas equipes de Atenção Primária à Saúde (APS) ${ }^{(15)}$. Um serviço de saúde organizado em redes, de forma horizontal, como o proposto pelas RAS, com vistas a resolver os problemas de saúde apresentados pelas crianças desde sua concepção, engloba inclusive a atenção direcionada à sua família, pois toda criança pertence a uma família, independente da configuração desta, seja tradicional ou não, cuja organização é resultante do contexto sociocultural e econômico que ela está inserida e não apenas biológica do homem.

Inserida na Rede Cegonha, em 2013, o MS instituiu a Estratégia Amamenta e Alimenta Brasil com o propósito de integrar a Rede Amamenta Brasil e a Estratégia Nacional para Alimentação Complementar Saudável (ENPACS). Para tanto, busca intensificar a promoção do aleitamento materno e alimentação saudável para crianças menores de dois anos e fortalecer as ações assistenciais a partir da qualificação no processo de trabalho dos profissionais da saúde ${ }^{(28)}$.

Nesse contexto, a partir das diferentes necessidades e direitos familiares, equipes de trabalho interdisciplinares devem tomar consciência da responsabilidade na construção de redes e apoio sociais as famílias, a fim de estruturá-las para garantir possibilidades de acolher e cuidar de seus seguimentos e construir o coletivo ${ }^{(8,15)}$. A construção das redes de atenção à saúde da criança e à saúde familiar estrutura-se e solidifica-se 
mediante um conjunto de elementos técnicos, científicos e subjetivos, os quais direcionam as ações para o cuidado com as pessoas. Essa forma de cuidar deve ainda ser iniciada no âmbito familiar, mas ao mesmo tempo, deve ser consolidada pelas ações desenvolvidas nos serviços públicos de saúde.

Ao analisar os índices de MI no Brasil desde a década de 1990, verifica-se que antes do prazo o país já atingiu uma das metas propostas nos ODM, ou seja, em 2011 apresentou um índice de $\mathrm{MI}$ de 16/1000 NV e reduziu dois terços à mortalidade para crianças menores de cinco anos até $2015^{(20)}$. Essa queda foi possível pelas importantes mudanças ocorridas ao longo do século XX, no que tange à melhoria nas condições de vida da população (pobreza, a educação das mulheres, a urbanização e a fertilidade), intervenções de outros setores, ou seja, transferências de renda e saneamento básico, as políticas públicas implementadas, incluindo a qualificação do acesso da população aos serviços de saúde, em todas as regiões geográficas) e os avanços do conhecimento em saúde e seus determinantes ${ }^{(16,18,25-26,29-30)}$.

Todavia, considerando que tanto no Brasil e quanto no mundo, a mortalidade concentrou-se e ainda concentra-se no período neonatal, principalmente decorrente de agravos perinatais, tal fato nos leva a perceber que a equidade proposta nas diretrizes do SUS não está sendo praticada integralmente. Somado as falhas na equidade percebem-se as diferenças regionais em termos de $\mathrm{MI}$, pois é possível observar dados bastante diferenciados entre as regiões do Brasil, caracterizados pela extrema diversidade regional existente e pelas condições sociais ${ }^{(16,18,25-26,29)}$.

Outra problemática evidenciada, na saúde da criança, relaciona-se às morbidades e hospitalizações por causas evitáveis no país. Entre as causas predominantes de morbidades que acometem crianças menores de quatro anos no Brasil, há a predominância de afecções respiratórias, seguidas por doenças infecciosas ou parasitárias, doenças do aparelho digestivo, por causas externas e, as doenças do aparelho geniturinário. Destaca-se que, tais doenças poderiam ser evitadas a partir de um conjunto de ações sensíveis e resolutivas ainda na $\mathrm{APS}^{(31)}$.

Esse cenário de morbidades por causas evitáveis mostra que, estratégias governamentais implementadas por meio de políticas públicas, poderiam possibilitar ainda mais a redução nas causas que levam ao adoecimento infantil mediante ampla cobertura à prevenção de doenças como: imunização; saneamento básico; ações educativas; cuidado com o meio ambiente; entre outros. Nesse sentido, a falta de ações de caráter preventivo e de promoção da saúde faz com que mortes evitáveis continuem acontecendo ${ }^{(18)}$, associada à vulnerabilidade em que se encontra a APS refletindo assim, no aumento dos índices de hospitalizações por causas evitáveis ${ }^{(31)}$.

Assim, aponta-se, ainda, como desafios para a redução da morbimortalidade infantil no Brasil, a redução da alta frequência de cesarianas, os abortos ilegais e os partos prematuros, além de investimentos para a redução das desigualdades regionais e socioeconômicas presentes em um país continental ${ }^{(30)}$.

É possível notar que todas as ações direcionadas à saúde da criança requerem transformações para mudar o panorama descrito. Visto que, não foram observadas ações efetivas por parte das políticas públicas, principalmente voltadas ao período perinatal. Mesmo com a redução dos índices de MI, a morbimortalidade nesta faixa etária ainda é considerada elevada no Brasil e no mundo e está relacionado às complicações perinatais e à prematuridade. Reconhece-se que mais de $60 \%$ de mortes precoces poderiam ter sido evitadas pelo acesso em tempo adequado a serviços de saúde de qualidade e resolutivos ${ }^{(18,22)}$. Assim como, a manutenção da morbidade relacionada à baixa resolutividade de acometimentos à saúde infantil considerado evitável, também se mantém elevada.

Nessa perspectiva, nota-se a urgência em implantar ou implementar políticas com vistas a melhorar a assistência ao segmento populacional infantil. Diante deste universo, percebe-se a não resolutividade dos problemas de saúde por parte dos serviços públicos no que se refere à saúde da criança, pois deficiências no acompanhamento ao crescimento e desenvolvimento da criança podem gerar uma condição crônica de saúde para esta faixa etária, uma vez que, existe um aumento progressivo da morbimortalidade por condições crônicas de saúde no Brasil. A ascendente complexidade epidemiológica observada nos serviços de saúde do país é decorrente de uma agenda não concluída de doenças infecciosas, desnutrição e dificuldades na saúde reprodutiva, somados ao inextricável conjunto de doenças crônicas e seus fatores de riscos e ao aumento gradativo dos problemas de saúde por causas externas ${ }^{(15)}$.

As estratégias governamentais não implementadas em sua totalidade no contexto da APS, remetem ao modelo assistencial vigente focado na atenção às doenças agudas e no atendimento às demandas espontâneas. Esse modelo converge a dificuldades de articulação entre os serviços de saúde e no seguimento a doenças crônicas, bem como na consideração dos determinantes sociais que interferem no processo saúde-doença da criança e da população(15).

\section{CONCLUSÃO}

A evolução histórica da participação da criança na sociedade, assim como os cuidados à saúde voltados a essa população, apresentou avanços, tendo como reflexo a redução da MI e implantação de diversas políticas públicas de saúde. Entretanto, como historicamente este fato é recente, muitas ações ainda precisam ser pontuadas, discutidas em profundidade, reorganizadas e pactuadas para que estes avanços possam realmente refletir as reais necessidades da população infantil.

A assistência à saúde da criança ainda encontra-se em processo de construção, juntamente com assistência à saúde em geral, em um movimento de mudança paradigmática do modelo centrado na patologia e na criança, para um modelo de construção de redes, em prol da inclusão da família e da integralidade do cuidado. Assim, ainda existem lacunas e limites no cuidado à criança, nas relações organizacionais e administrativas, no fortalecimento das políticas públicas estaduais e municipais, no modelo de processo de trabalho e no processo continuado de educação em saúde.

Os profissionais de saúde envolvidos no cuidado à criança devem desenvolver suas atividades, tendo por base implementar as políticas públicas vigentes que garantam a qualidade da atenção à população infantil. Esta atuação inclui, desde 
a qualificação do aconselhamento para uma vida sexual saudável com os adolescentes, destaque para o espaço escolar como campo de promoção da saúde, passando pelo pré-natal, parto e cuidados imediatos com o recém-nascido, buscando a diminuição dos agravos no período perinatal.
Para tanto, é preciso investir na qualificação da formação de recursos humanos para esta área, com ênfase nas políticas públicas, tendo em vista à promoção e prevenção em saúde e, por conseguinte, à melhor qualidade de vida dessa população.

\section{REFERÊNCIAS}

1. Ariés P. História social da criança e da família. 2. ed. Rio de Janeiro: Livros Técnicos e Científicos; 2011.

2. Faleiros VP. Políticas para a infância e adolescência e desenvolvimento [Internet]. [local desconhecido]: IPEA; 2005 [acesso em 22 fevereiro de 2012]. Disponível em: http://www.ipea.gov.br/agencia/images/stories/PDFs/politicas_sociais/ENSAIO1_Vicente11.pdf

3. Costa R, Padilha MI, Monticelli M, Ramos FRS, Borenstein MS. Políticas Públicas de Saúde ao recém-nascido no Brasil: reflexos para a assistência neonatal. Hist Enferm Rev Eletronica [Internet]. 2010 [acesso em 22 fevereiro de 2012];1(1):55-68. Disponível em: http://www.abennacional.org.br/centrodememoria/here/n1vol1ano1_artigo4.pdf

4. Silva LR, Christoffel MM, Souza KV. História, conquistas e perspectivas no cuidado à mulher e à criança. Texto \& Contexto Enferm [Internet]. 2005 [acesso em 22 fevereiro de 2012];14(4):585-93. Disponível em: http://www.scielo.br/pdf/tce/v14n4/a16v14n4.pdf

5. Marcílio ML. História social da criança abandonada. São Paulo: Hucitec; 1998.

6. Ribeiro PRM. História da saúde mental infantil: a criança brasileira da colônia à república velha. Psicol Estud [Internet]. 2006 [acesso em 22 fevereiro de 2012];11(1):2938. Disponível em: http://www.scielo.br/pdf/pe/v11n1/ v11n1a04.pdf

7. Foucault M. A microfísica do poder. 25. ed. Rio de Janeiro: Graal; 2012.

8. Kaloustian SM. Família brasileira a base de tudo. 2. ed. São Paulo: Cortez; Brasília (DF): UNICEF; 1994.

9. Lopes SB, Moreira MCN. Quando uma proposição não se converte em política? O caso da Política Nacional de Atenção Integral à Saúde de Adolescentes e Jovens PNAISAJ. Ciênci Saúde Coletiva [Internet]. 2013 [acesso em 22 fevereiro de 2012];18(4):1179-86. Disponível em: http://www.scielosp.org/pdf/csc/v18n4/31.pdf

10. Silva MA. Política de saúde para crianças: apontamentos para a atuação da enfermagem. In: Gaíva MAM. Saúde da criança e do adolescente: contribuições para o trabaIho de enfermeiros(as). Cuiabá: Universidade Federal do Mato Grosso; 2006. p. 9-28.

11. Ministério da Saúde (BR). Gestão e gestores de políticas públicas de atenção à saúde da criança: 70 anos de história [Internet]. Brasília (DF): Ministério da Saúde; 2011 [acesso em 22 fevereiro de 2012]. Disponível em: http:// www.redeblh.fiocruz.br/media/70ahsaudecrianca.pdf

12. Perez JRD, Passone EF. Políticas sociais de atendimento às crianças e aos adolescentes no Brasil. Cad Pesqui [Internet].
2010 [acesso em 22 fevereiro de 2012];40(140):649-73. Disponível em: http://www.scielo.br/pdf/cp/v40n140/ a1740140.pdf

13. Ministério da Saúde (BR). Óbitos infantis no Brasil. [Internet]. [local desconhecido]: Ministério da Saúde; [atualizado em 18 de novembro de 2014; acesso em 07 agosto de 2014]. Disponível em: http://tabnet.datasus.gov.br/cgi/ deftohtm.exe?sim/cnv/inf09uf.def

14. Frias PG, Mullachery PH, Giugliani ERJ. Políticas de saúde direcionadas às crianças brasileiras: breve histórico com enfoque na oferta de serviços de saúde. In: Saúde Brasil 2008: 20 anos de Sistema Único de Saúde (SUS) no Brasil [Internet]. 2008 [acesso em 09 de dezembro de 2013]. Disponível em: http://bvsms.saude.gov.br/bvs/publicacoes/saude brasil 2008.pdf

15. Mendes EV. O cuidado das condições crônicas na atenção primária à saúde: o imperativo da consolidação da estratégia da saúde da família [Internet]. Brasília (DF): Organização Pan-Americana da Saúde; 2012 [acesso em 22 fevereiro de 2012]. Disponível em: http://bvsms.saude. gov.br/bvs/publicacoes/cuidado_condicoes_atencao_primaria_saude.pdf

16. Ministério da Saúde (BR). Atenção à saúde do recémnascido. Guia para os profissionais da saúde [Internet]. Brasília (DF): Ministério da Saúde; 2011 [acesso em 22 fevereiro de 2012]. Disponível em: http://www.redeblh. fiocruz.br/media/arn_v1.pdf

17. Pina JC, Mello DF, Mishima SM, Lunardelo SR. Contribution of a shelter-based integrated management of childhood illnesses program for children under the age of five years. Acta Paul Enferm [Internet] 2009 [cited 2012 February 22];22(2):142-8. Available from: http://www.scielo.br/scielo.php?pid $=$ S0103-21002009000200005\&script $=$ sci abstract

18. Ministério da Saúde (BR). Manual de vigilância do óbito infantil e fetal e do comitê de prevenção do óbito infantil e fetal [Internet]. Brasília (DF): Ministério da Saúde; 2009 [acesso em 22 fevereiro de 2012]. Disponível em: http:// bvsms.saude.gov.br/bvs/publicacoes/manual obito infantil fetal 2ed.pdf

19. Ministério da Saúde (BR). Atenção humanizada ao recémnascido de baixo peso: método mãe-canguru: manual técnico. Secretaria de Políticas de Saúde. Área da Saúde da Criança. 2. ed. Brasília (DF): Ministério da Saúde; 2011.

20. Odmbrasil.gov [Internet]. [localização desconhecida]: Ministério da Saúde; 2012 [acesso em 16 de outubro de 2013]. Disponível em: http://www.odmbrasil.gov.br/ odmbrasil/o-brasil-e-os-odm 
21. Silva ACMA, Villar MAM, Wuillaume SM, Cardoso MHCA. Perspectivas de médicos do programa saúde da família acerca das linhas de cuidado propostas pela agenda de compromissos para a saúde integral da criança e redução da mortalidade infantil. Cad Saúde Pública [Internet]. 2009 [acesso em 22 fevereiro de 2012];25(2):349-58. Disponível em: http://www.scielo.br/pdf/csp/v25n2/13.pdf

22. Ministério da Saúde (BR). Agenda de compromissos para a saúde integral da criança e redução da mortalidade infantil [Internet]. Brasília (DF): Ministério da Saúde; 2004 [acesso em 22 fevereiro de 2012]. Disponível em: http:// bvsms.saude.gov.br/bvs/publicacoes/agenda_compro_ crianca.pdf

23. Ministério da Saúde (BR). Portaria $n^{\circ}$. 2799, de 18 de novembro de 2008. Institui, no âmbito do Sistema Único de Saúde - SUS, a Rede Amamenta Brasil. Diário Oficial União 19 nov 2008;Seção 1.

24. Passanha A, Benício MHD, Venâncio SI, Reis MCG. Implantação da Rede Amamenta Brasil e prevalência de aleitamento materno exclusivo. Rev Saúde Pública [Internet]. 2013 [acesso em 15 outubro de 2014];47(6):1141-8. Disponível em: http://www.scielo.br/pdf/rsp/v47n6/00348910-rsp-47-06-01141.pdf

25. Ministério da Saúde (BR). Portaria $n^{\circ}$. 2.395, de 7 de outubro de 2009. Institui a Estratégia Brasileirinhas e Brasileirinhos Saudáveis e cria o comitê técnico- consultivo para a sua implementação. Diário Oficial da União 09 out 2009;Seção 1.

26. Ministério da Saúde (BR). Portaria $n^{\circ} 1.459$, de 24 de junho de 2011. Institui no âmbito do Sistema Único de
Saúde -SUS - a Rede Cegonha. Diário Oficial da União 27 jun 2011;Seção 1.

27. Ministério da Saúde (BR). Portaria $n^{\circ} 4.279$, de 30 de dezembro de 2010. Estabelece diretrizes para a organizaçãp da Rede de Atenção à Saúde no âmbito do Sistema Único de Saúde (SUS). Diário Oficial da União 31 dez 2010;Seção 1.

28. Ministério da Saúde (BR). Portaria $n^{\circ} 1.920$, de 5 de setembro de 2013. Institui a Estratégia Nacional para Promoção do Aleitamento Materno e Alimentação Complementar Saudável no Sistema Único de Saúde (SUS) - estratégia Amamenta e Alimenta Brasil [Internet]. Diário Oficial da União 06 set 2013 [acesso em 16 outubro de 2014];Seção 1. Disponível em: http://bvsms.saude.gov.br/ bvs/saudelegis/gm/2013/prt1920_05_09 2013.html

29. Ministério da Saúde (BR), Secretaria de Atenção à Saúde. Pacto pela redução da mortalidade infantil no nordeste e Amazônia legal 2009-2010 [Internet]. Brasília (DF): Ministério da Saúde; 2010 [acesso em 16 de outubro de 2014]. Disponível em: http://abenfo.redesindical.com.br/ arqs/manuais/030.pdf

30. Victora CG, Aquino EML, Leal MC, Monteiro CA, Barros FC, Szwarwald CL. Maternal and child health in Brazil: progress and challenges. Lancet. 2011;377(9780):1863-76.

31. Oliveira BRG, Viera CS, Collet N, Lima RAG. Causes of hospitalization in the national healthcare system of children aged zero to four in Brazil. Rev Bras Epidemiol [Internet]. 2010 [cited 2014 October 16];13(2):268-77. Available from: http://www.scielo.br/pdf/rbepid/v13n2/ en_09.pdf 